Journal of Al-Azhar University Engineering Sector

Vol.17, No.62 ,2022, 161 - 171

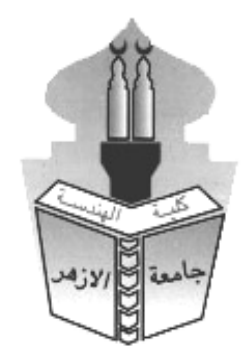

\title{
WATER QUALITY MANAGEMENT FOR SUSTAINABLE DEVELOPMENT OF LAKE BURULLUS
}

Mohamed Ahmed Reda Hamed

Assistant Prof. in Civil Engineering Dept., Canadian International Colleague (CIC), El Sheikh Zayed, Giza, Egypt.

Received :2 Nov. 2021 Accepted:8 Dect. 2021

\begin{abstract}
Lake Burullus, the second largest lake on the northern coast of Egypt, is suffering a serious deterioration in water quality due to the huge amounts of water contaminated with fertilizers and pesticides. This resulted in a significant reduction in the area of the lake and a severe degradation of its ecosystem, including decreased yields from fisheries, consequently creating serious socioeconomic challenges for local fishing communities and affecting Egypt's national fish production. A few years ago, the Egyptian government did everything possible to rehabilitate and restore Lake Burulls through a major improvement project to restore ecological and economic values. However, the main objective of this research is to assess and analyze the general environmental conditions of the current lake to manage the future development of the lake's sustainability. Therefore, Delft 3D flow module was developed and calibrated to simulate lake hydrodynamic. Moreover, many proposed scenarios introducing integrated solutions to overcome current and future water quality challenges. The results of the study confirmed that the use of sewer wastewater treatment scenarios for drain discharges is strongly recommended. Furthermore, the construction of an additional new artificial Inlet (Boughaz) can achieve the exchange of water with the sea and the necessary lake circulation scheme, but has the disadvantage of increasing the average salinity of the lake. The study concluded that the developed model is efficiently simulates the hydrodynamics of the lake and can serve as an effective decision-making tool for future remediation projects to maintain environmental improvement.
\end{abstract}

KEYWORDS: Water Quality, Lake Burullus, Delft 3D, Circulation Patterns, Hydrodynamics.

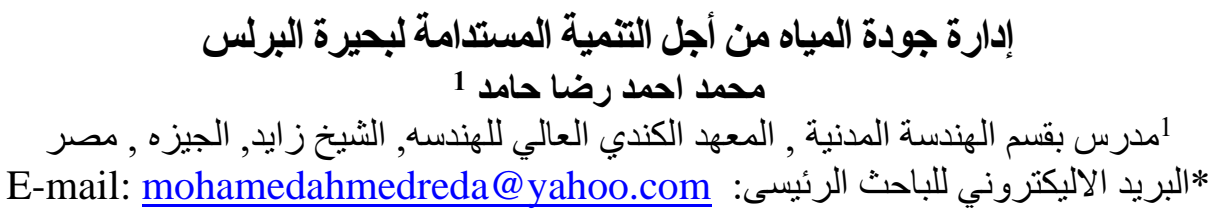




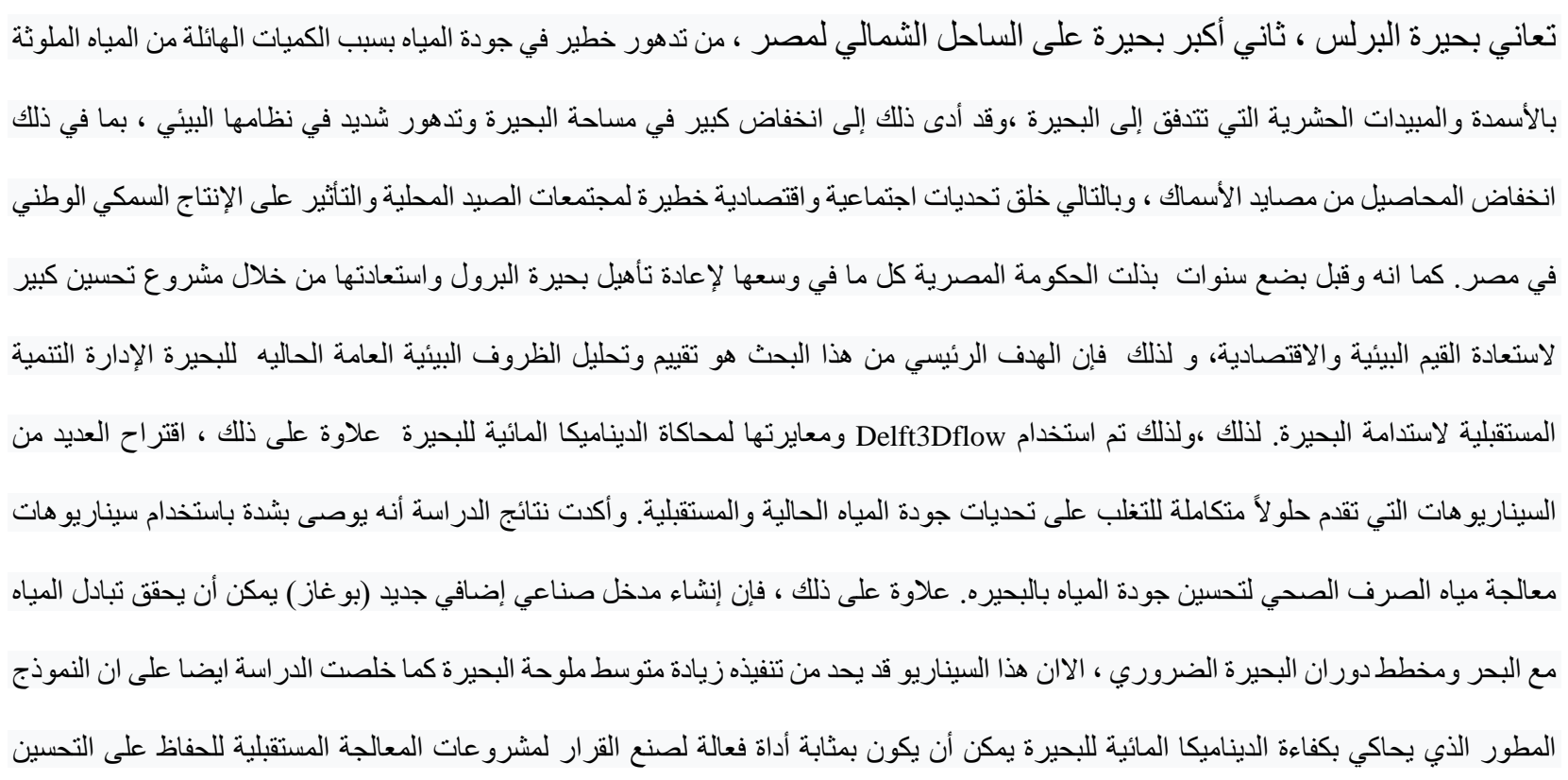

البيئي.

الكلمات المفتاحية : الخصائص جودة المياه ، بحيرة البرلس ، Delft 3D ، أنماط الدوران والسريان الهيدروليكي

\section{INTRODUCTION}

Burullus Lake that has important economic and environment values in Egyptian northern lakes suffering from pollution challenges from many decades [1]. Pollution within the lake is due to chemical pollution from industrial growth in the area. The lake's nutrient-rich environment allows for extensive growth of floating plants. In addition, the TSS values of total suspended solids are very high, which means that the high levels of contamination of organic and inorganic materials from industrial and agricultural waste [2].

The Egyptian government also recently implemented the Burullus rehabilitation project, which included dredging the entry point, border protection on both sides of the entrance, lateral protection on the northwest side of the lake, and radial channel at the inlet location, figure (2).

Delft3D (developed by Delft Hydraulics) offers a sophisticated three-dimensional modeling system that can provide three-dimensional currents, surface waves, water quality, ecology, sediment transport, and soil morphology in complex coastal areas [3]. 


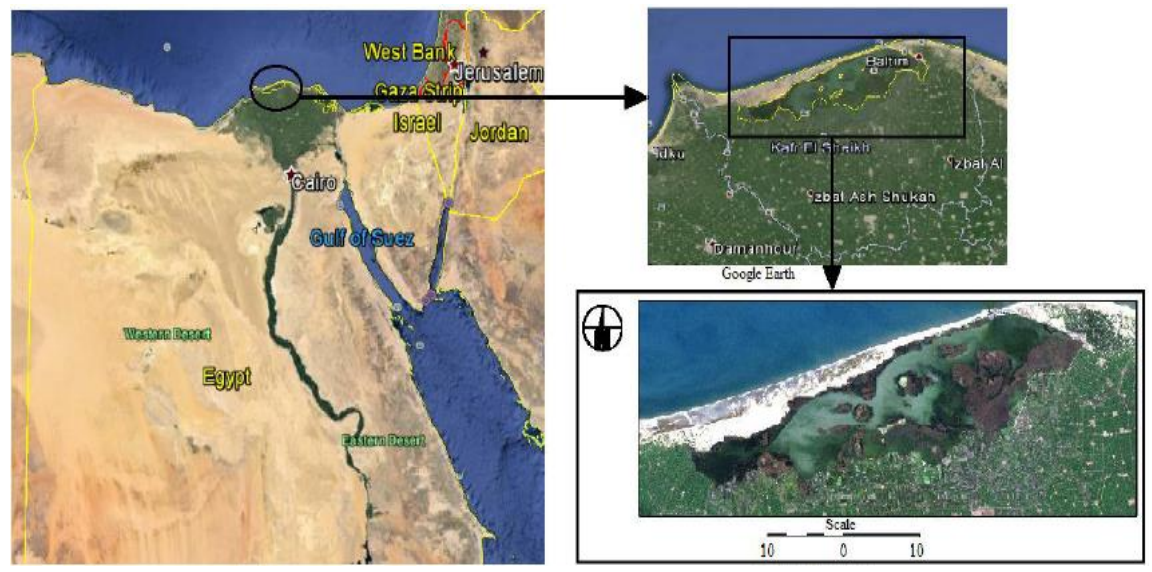

Fig. 1 Lake Burulus Location
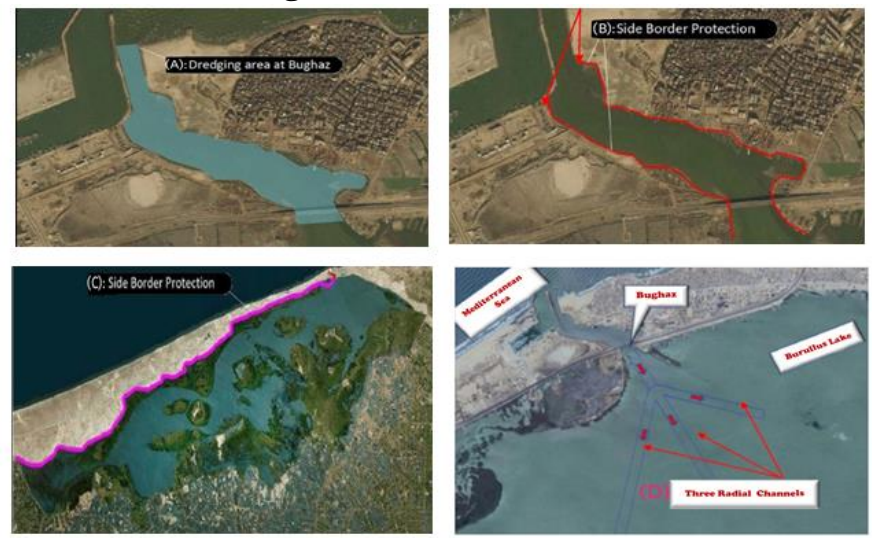

Fig. 2 Burulus rehabilitation project A: Dredging the inlet location, B: Inlet border protection, C: Northwest lake side protection, and D: Inlet radial channel

\section{Study area}

Figure (3) shows the geographic location of Lake Burullus between longitudes 30030' - 31010' E and latitudes 31035 '- 31021' $\mathrm{N}$ and latitudes 31035 '- 31021' N.It can be noted that Brimbal Canal in the lake west and Eight drains discharge into Burullus Lake [4]. 


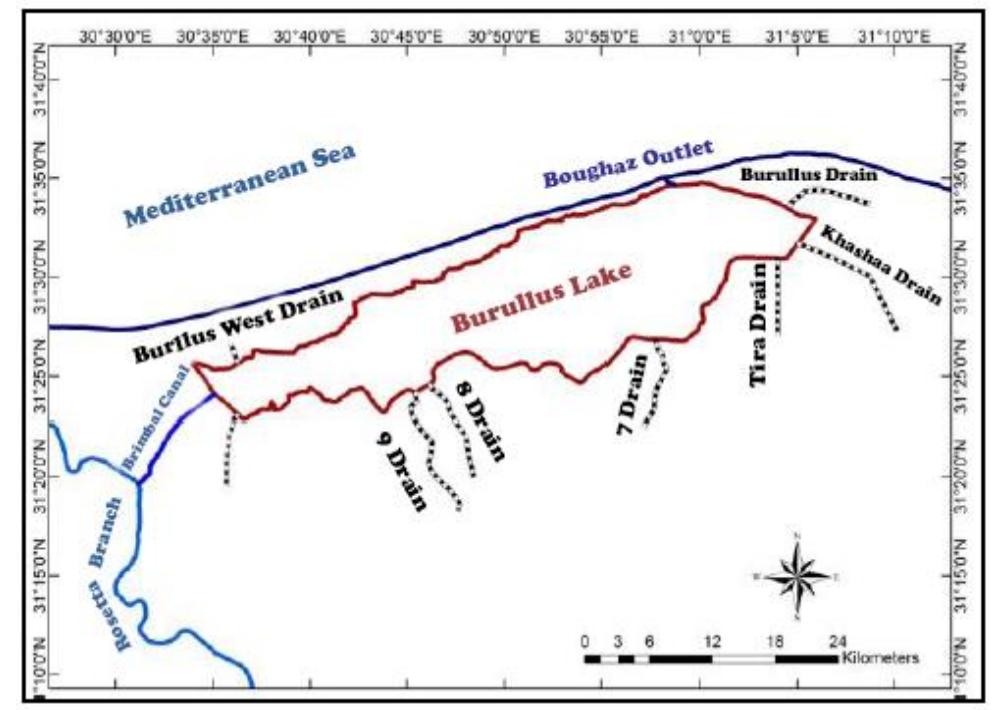

Fig. 3: The Geographic Location of Lake Burullus

\section{Materials and Methods}

\subsection{Sampling Sites}

During two subsequent years (2019 and 2020), twelve surface water sampling station were observed, which express the degree of presence in the field directly and seasonally. Sampling sites were selected that cover the different locations of Lake Burulus, Figure (4).

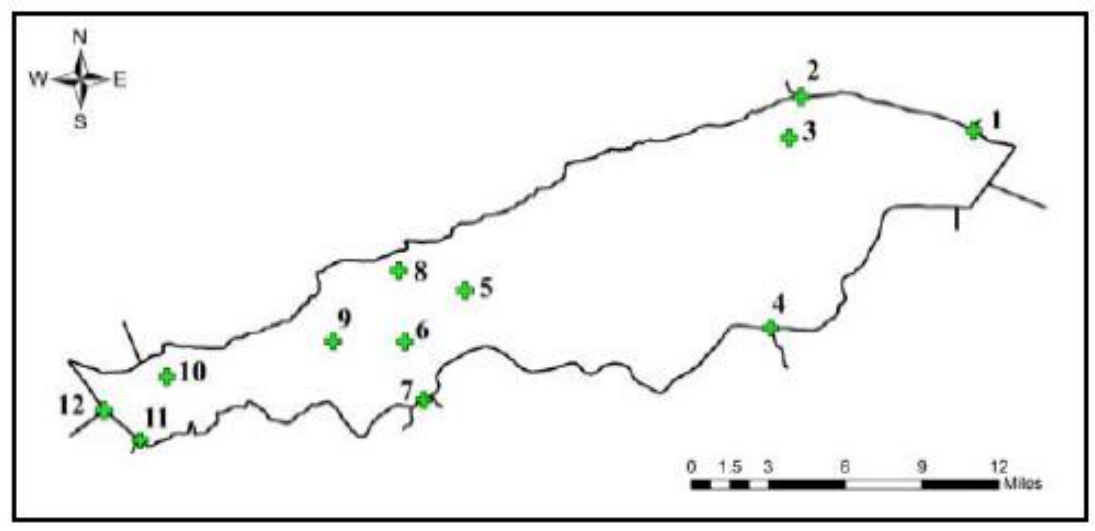

Fig. 4: Selected Sampling Stations of Burulus Lake

\subsection{Methods}

Figure (5) illustrates the main study procedures 


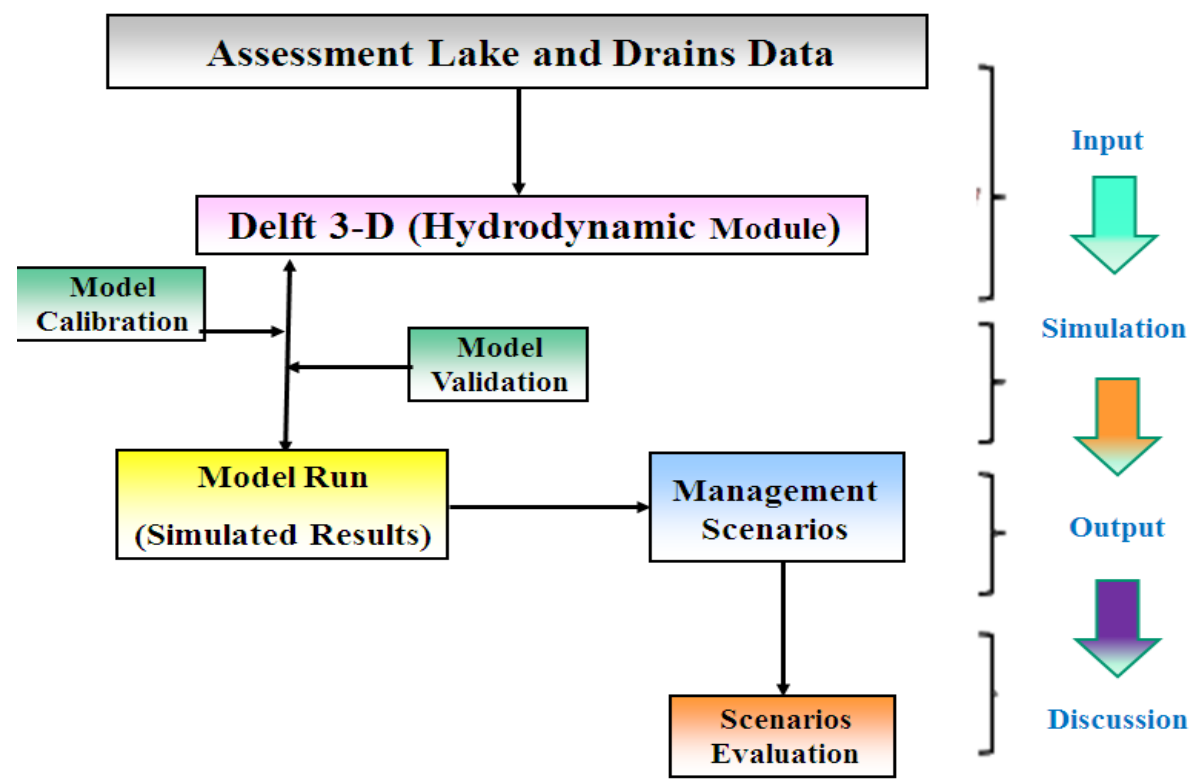

Fig. 5: Study Procedures

\subsection{Hydrodynamic Model}

The Delft 3D flow module and the WAQ module were used for the simulation of water quality. The main flow equations solved by Delft 3D are: Continuity equation, Momentum equation and Navier- Stokes equation. Runoff, water levels, tidal fluctuations as components of hydrodynamic data sets and vectors of wind, solar radiation, relative humidity, and temperatures as components of meteorological data sets are used for the process. In addition, geometric data such as bathymetry, land boundaries, island boundaries, and drainage positions were used to determine the open and closed boundaries of the model and to create the grids.

\section{Results and Discussion}

\subsection{Hydrodynamic Model Calibration and Validation}

The hydrodynamic model was calibrated and validated to meet both the accuracy and stability of the simulated seawater quality results. The model was spatially calibrated against various results of the measured salinity. Figure (6) shows the simulated salinity of the lake, while Figure (7) shows the simulated salinity compared to the corresponding observed salinity of the lake. 


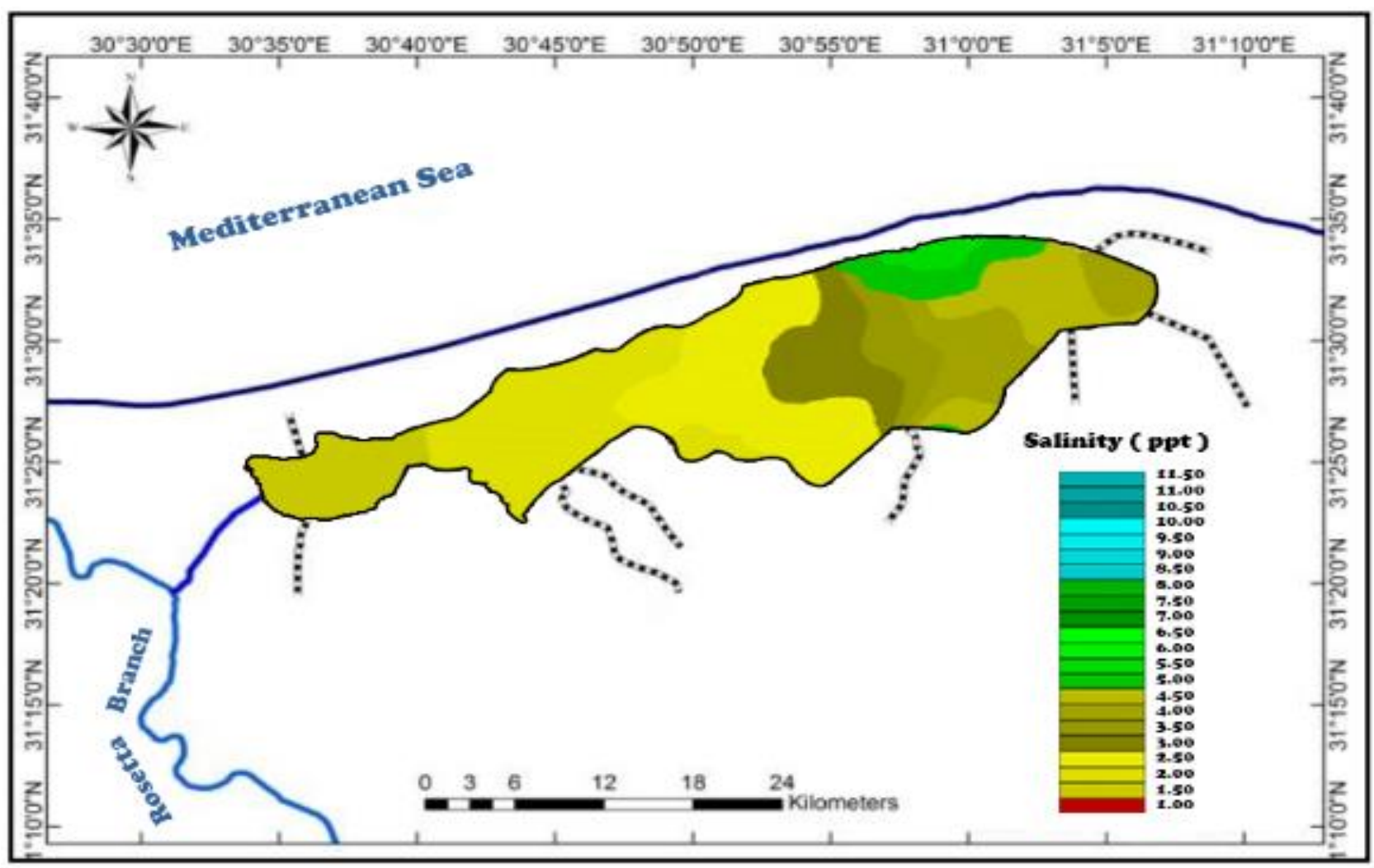

Fig. 6 Lake Burulus Simulated Salinity

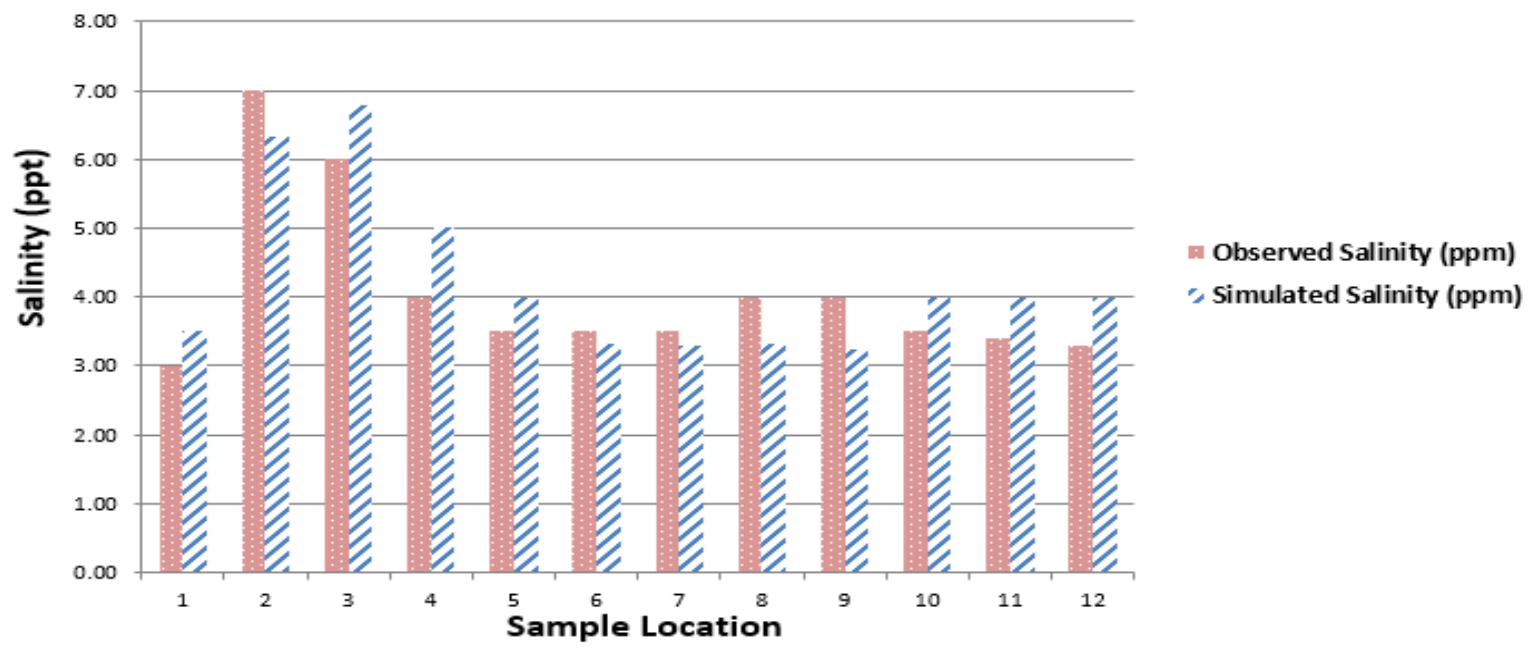

Fig. 7 Observed and Simulated Salinity

The simulated and observed salinity results at different samples locations shows that there is a slight difference between two corresponding values, which also indicated by perfect relation with correlation factor equal 0.92 . 
The salinity distribution reduces from east to west. In particular, due to the implementation of the lake rehabilitation project including radial channels. An expected salinity increasing at the inlet entry point. Furthermore, figures $(8 \mathrm{a}, \mathrm{b}$, and $\mathrm{c})$ illustrate the annual mean values of the simulated $\mathrm{DO}, \mathrm{BOD}, \mathrm{COD}$, and $\mathrm{NH}_{4}$ results.
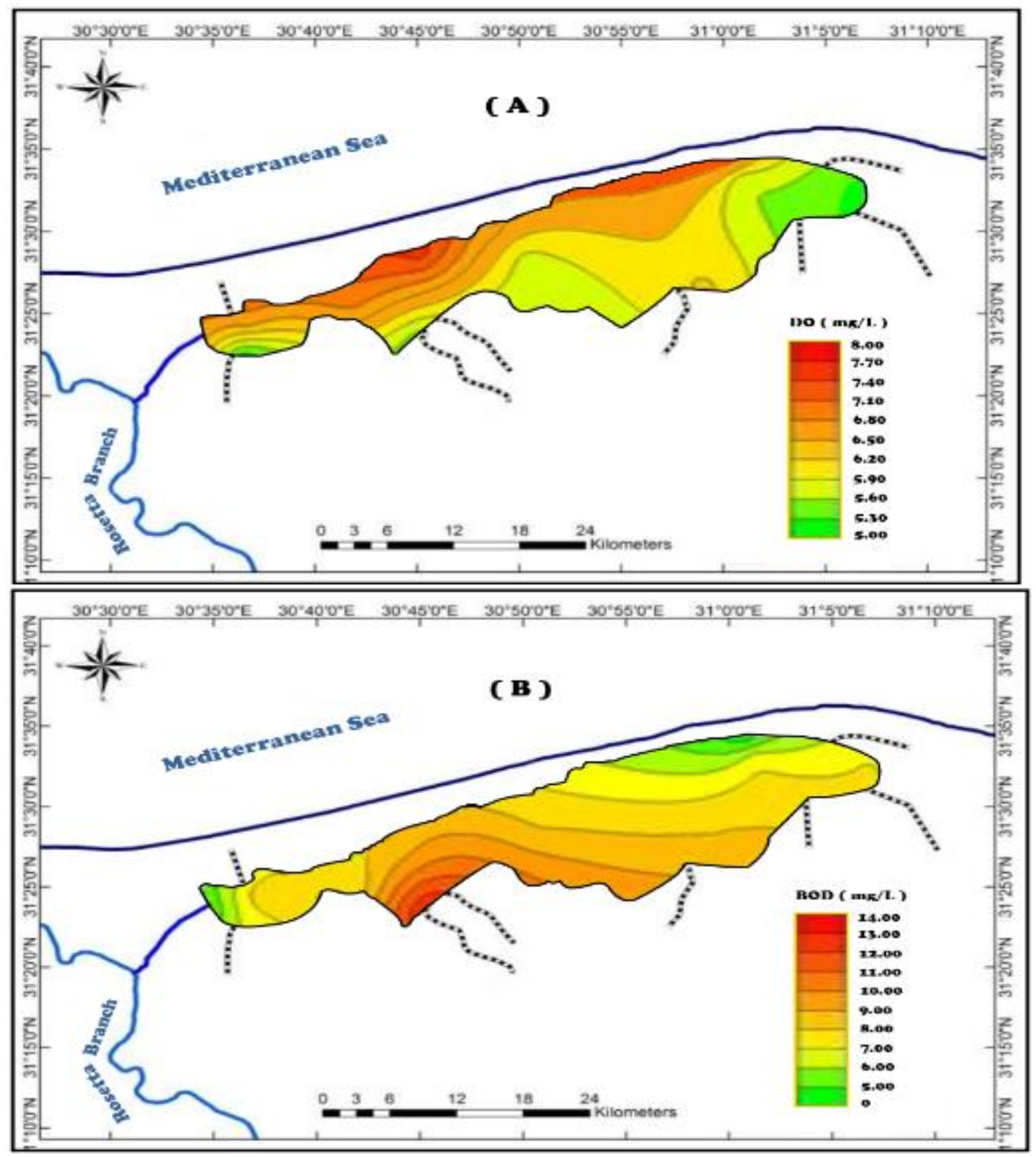

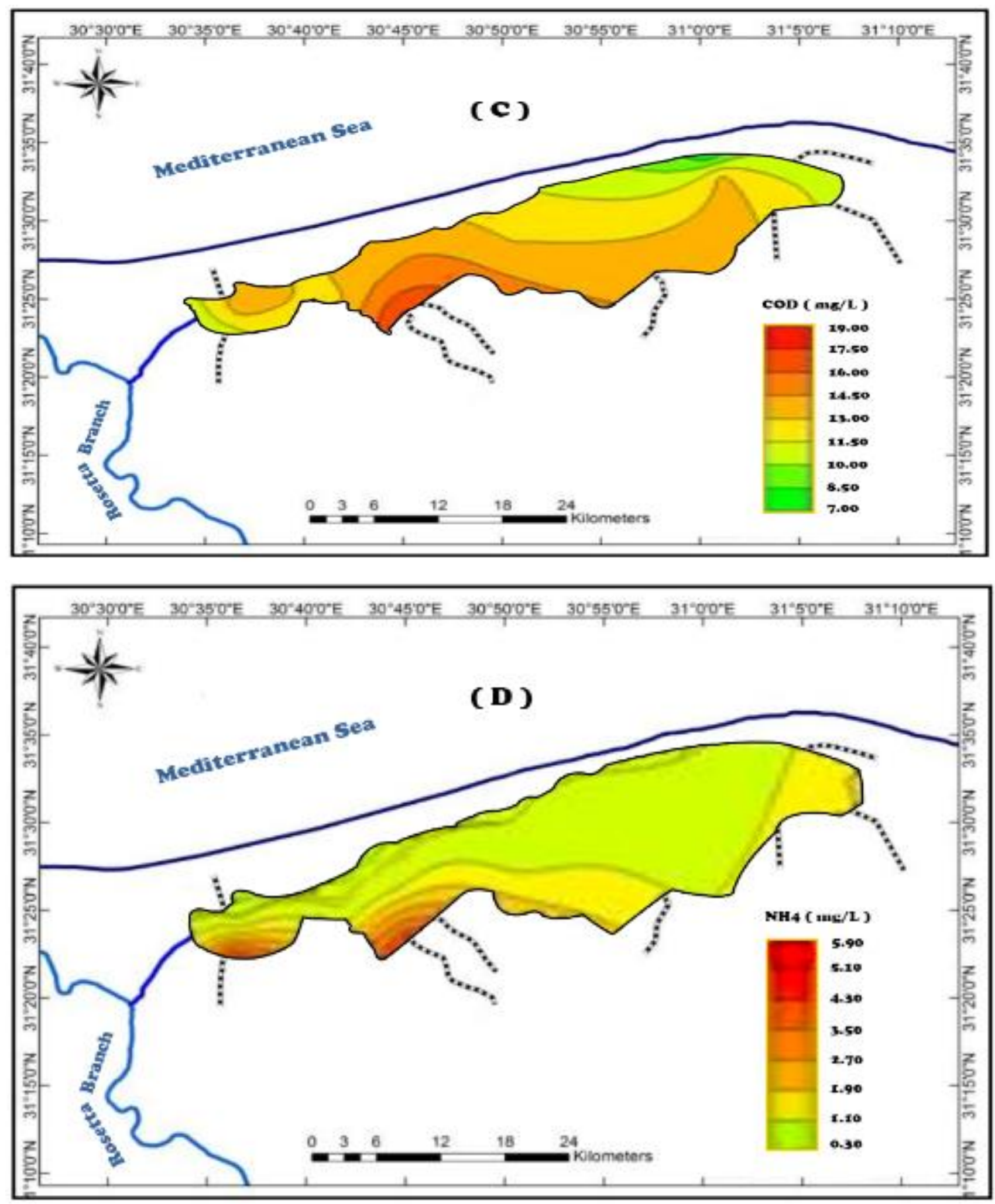

Fig. 8 Spatial Distribution of A: DO, B: BOD, C: COD, and D: NH4 (mg/l) Lake Burulus 
According to the shown water quality basic simulated parameters, it can be seen that dissolved oxygen (DO) decreased from north to south due to the largest amount of wastewater received from eight agricultural discharges. In addition, the biological oxygen demand (BOD) in the southern locations of the lake has the highest values due to the influence of the sewage system, but reaches the minimum concentration in the northern locations. The worst polluting drains in the drainage system were drain No. 11 and Bahr Nashart drain with respect to studied water quality parameters Thus, the high BOD levels indicate that the sewage inflow and domestics waste from drains didn't satisfy Law 48/1982 (mustn't exceed 10mg/l). Moreover, in most of the lake various parts, a noted exceedance for chemical oxygen demand (COD) to the permissible national limit (maximum permissible $10.00 \mathrm{mg} / \mathrm{l})$. Furthermore, the simulated values of ammonium $\left(\mathrm{NH}_{4}\right)$, showing the highest concentrations in the area around drains 8 and 9. Excessive levels of ammonia can harm life in the water and are an indicator of poor water quality. Excessive usage of ammonia rich fertilizers causes ammonia problem in the streams. Law 48 specified that the ammonia level in drainage water must not exceed $0.5 \mathrm{mg} / \mathrm{l}$.

\subsection{Water Quality Management Scenarios}

To solve the water quality problems of Lake Burulus, the calibrated model was used to study the application of some water quality management scenarios in the lake in order to maintain a better lake ecosystem. However, six proposed scenarios: construction of a new artificial drain for the lake and application of water quality treatment techniques for polluting drains. Figure (9) gives a schematic representation for the suggested Lake Burullus water quality management scenarios. While, figure (10) shows the results of the proposed water quality management scenarios.

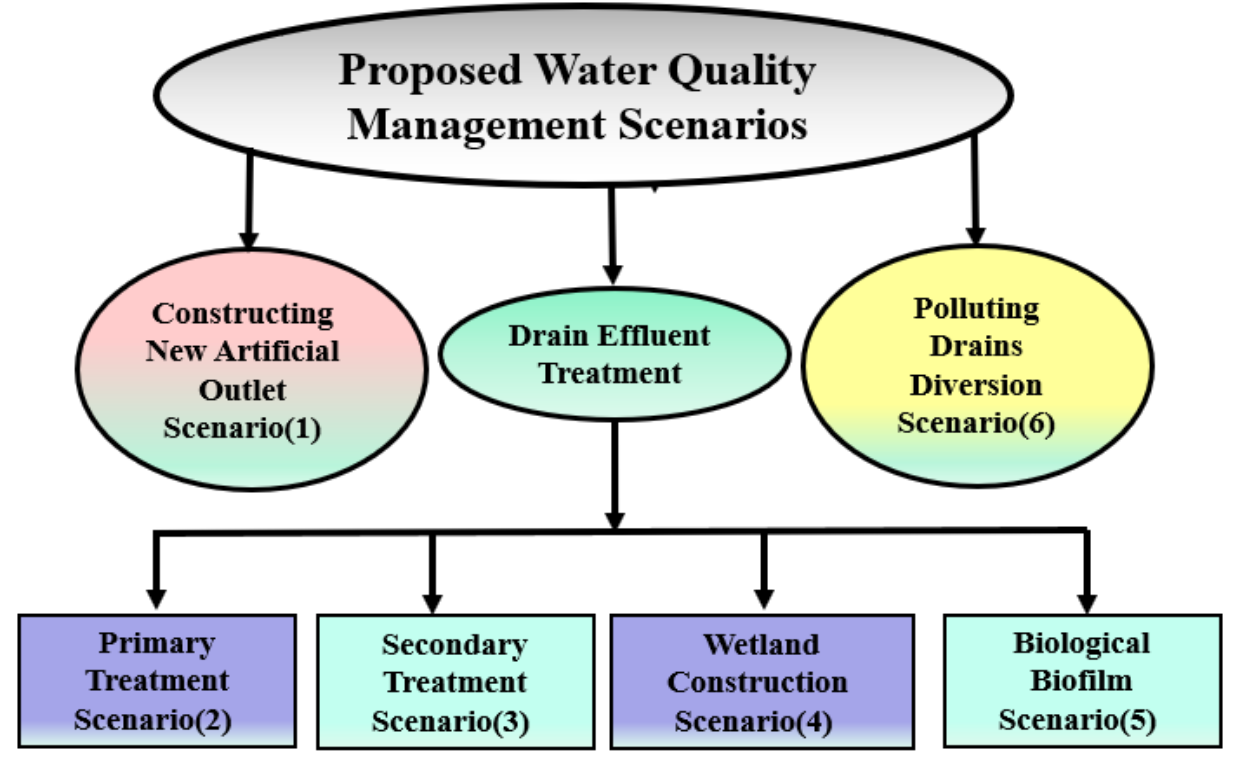

Fig. 9 Lake Burullus Water Quality Management Scenarios 

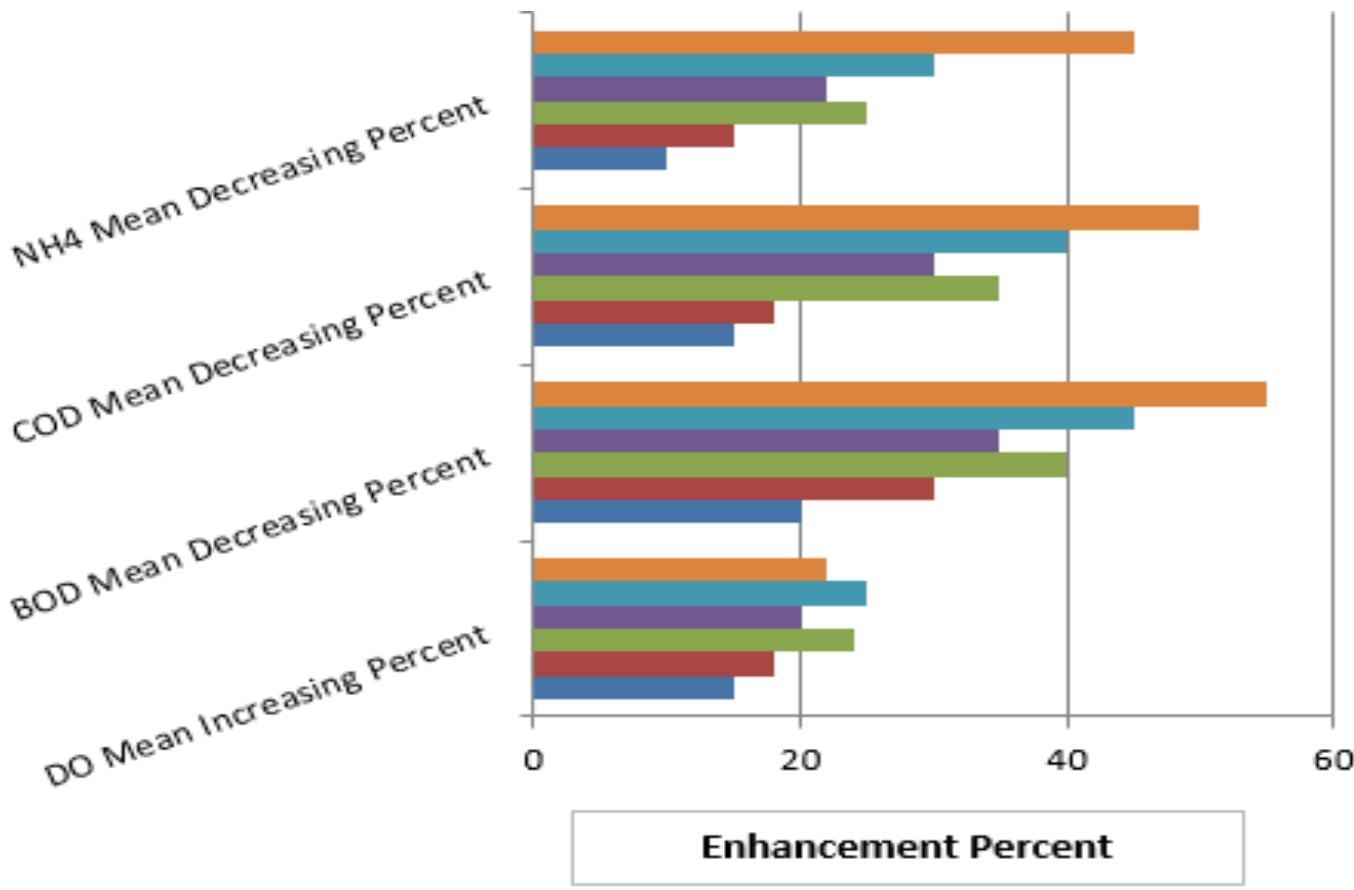

- Senario (6)

Senario (5)

Senario (4)

Senario (3)

Senario (2)

Senario (1)

Fig. 10 Water Quality Management Scenarios Results

Scenario (1) proposes constructing artificial inlet at distance of $15 \mathrm{~km}$ west to the existence outlet "El-Boughaz" with an average depth from $2 \mathrm{~m}$ to $3 \mathrm{~m} \mathrm{~m}$ to increase exchange rates between the lake and the Mediterranean Sea. However, a more efficient circulation pattern can be achieved within the lake. On the other hand, the disadvantage of this scenario is that it is directly related to the increase in the salinity of the lake. While Scenario (2) involved in applying primary treatment technique for study area polluted drains, but this scenario has a relatively limited influence on lake water quality improvement. In addition, scenario (3) suggests the use of secondary treatment techniques instead of primary treatment, which shows a relatively large improvement in water quality compared to the first scenario, but three are many noted limitation on applying this scenario especially with regard to long run technical and environmental efficient sustainability. In addition, Scenario (4) suggests applying the surface stream wetland technique to assist in BOD and $\mathrm{NH}_{4}$ reduction, despite limited social impact due to the impact of stakeholder buy-in, health and safety risks. To solve lake's BOD problem, wetland technique was the most economic and effective scenario. Scenario (5) suggests applying biological biofilm technique for drains effluent treatment. However, this scenario can enhance lake water quality characteristics but the limitation behind applying this technique is its high total cost. Scenario (6) involves in diverting the most polluting drains to reduce pollution load. However, it is suggested to divert drains 7, 8 and 11 so that no adjacent drains are diverted.in order to control lake pollution. The limitation of applying this scenario can be consider in its inversely effects on decreasing lake water level.

\section{CONCLUSIONS}

- Lake Burullus receives a large amount of its water from its tributary drainages which cannot meet the limit required by law 48/1982, so the tributary drains are considered the main source of contamination of the lake. 


\section{WATER QUALITY MANAGEMENT FOR SUSTAINABLE DEVELOPMENT OF LAKE BURULLUS}

- Hydrodynamic Delft 3D Model results were successfully calibrated and run to simulate lake water quality characteristics.

- In this research an evaluation of Lake Burullus and its polluting discharges was carried out and scenarios were proposed to solve the problems of drains problems.

- The variables of the state of water quality, salinity, DO, COD, BOD and NH4 modeled in the study depend on the concentration of effluents entering the various inputs.

-This study should serve as a guide for decision makers in applying water quality management plans for Lake Burullus.

- Furthermore, A permanent monitoring system should be established to obtain continuous records of lake hydrodynamic and water quality parameters.

\section{REFERENCES}

1. Ahmed MH, Abdel-Moati MAR, El-Bayomi G, Tawfik M, El-Kafrawi S. Using geo-information and remote sensing data environmental assessment of Burullus Lagoon, Egypt. Bulletin of the National Institute of Oceanography and Fisheries (Egypt), 2001;27.

2. Shalby A, Elshemy M, Zeidan BA. Assessment of climate change impacts on water quality parameters of Lake Burullus, Egypt. Environ Sci Pollut Res 2020;27(26):32157-78. doi: https://doi.org/10.1007/s11356-019-06105-x.

3. El-Adawy A, Negm AM, Elzeir MA, Saavedra OC, El-Shinnawy IA, Nadaoka K. Modeling the Hydrodynamics and Salinity of El-Burullus Lake (Nile Delta, Northern Egypt). Journal of Clean Energy Technologies; 2013. https://doi.org/ 10.7763/jocet.2013.v1.37.

4. Salah, Ayyad1, Distribution pattern and environmental controls on benthic foraminifera in elburullus lake, north of the Nile delta, Egypt, journal of environmental sciences, 2010.

5. El-Shinnawy, I.A.E. Water Budget Estimate for Environmental Management at Al-Burullus Lake, Egypt. In Proceedings of the 4th International Conference and Exhibition for Environmental Technologies Environment, Cairo, Egypt, 24-28 November 2003.

6. Negm. Egyptian Coastal Lakes and Wetlands: Part II Climate Change and Biodiversity. 2019;49(0): 6221.

7. Assar W, Elshemy, Zeidan, Water quality modeling for Lake Burullus, Egypt, Part I: Model Calibration. (Dept.C (irrigation)). Bull Faculty Eng. Mansoura University 2018;40(2):54-61. https://doi.org/10.21608/bfemu.2020.101244.

8. Ahmed Hany Fatma Akl, Mona Hagras, Ahmed Balah a,c. Assessment of recent rehabilitation projects' impact on water quality improvement in Lake Burullus, EgyptJ 2016;7(2):527-41. (http://creativecommons.org/licenses/by-nc-nd/4.0/).

9. Soliman, Ushijima S. Climate change impact on El-Burullus lake salinization process. J Jpn Soc Civil Eng Ser. B1 (Hydraulic Engineering) 2013;69(4). doi:https://doi.org/10.2208/jscejhe.69.i_253. 